\title{
A Real-Life Picture of the Origin of a Tumor
}

\author{
Ronald L. Huston \\ Department of Mechanical and Material Engineering, University of Cincinnati, Cincinnati, USA \\ Email: ron.huston@uc.edu
}

How to cite this paper: Huston, R.L. (2018) A Real-Life Picture of the Origin of a Tumor. Advances in Bioscience and Biotechnology, 9, 373-377.

https://doi.org/10.4236/abb.2018.98024

Received: July 13, 2018

Accepted: August 17, 2018

Published: August 20, 2018

Copyright $\odot 2018$ by author and Scientific Research Publishing Inc. This work is licensed under the Creative Commons Attribution International License (CC BY 4.0).

http://creativecommons.org/licenses/by/4.0/

\begin{abstract}
This paper provides an explicit representation of malignant cell division. To put this in perspective, the paper also provides a summary review of cellular division and duplication. Finally, a theory of tumor/cancer initiation following carcinogenic exposure is presented.
\end{abstract}

\section{Keywords}

Tumor Development, Cancer, Breast Cancer, Cell Division

\section{Introduction}

Figure 1 shows the picture of a tumor being made, via two cells. In the lower cell, we can clearly see the nucleus (in blue) separated into five parts (whereas in a normal cell the nucleus is a single unit).

As the cells continue to develop, each nucleus part evolves into nuclei of a new cell. If now these new cells also have five-part nuclei, then with succeeding cycles, the number of cells increases exponentially, and a tumor is created.

The cells of Figure 1 are breast cancer carcinomas. They are stained with Blue-Dapi (staining the nucleus), Red_Alpha Tubulin (staining microtubules) and Green-Pericentric (staining the 13 blades of a centriole).

The credit for this picture goes to Christy Caudill, BS, a Research Associate of the Schafer Foundation.

\section{Normal Cell Division}

To place the multi-nuclei parts of Figure 1 into context, it is helpful to review the makings of normal cell division and duplication. This process has been studied for many years. References [1]-[6] document these efforts.

Figure 2 provides a drawing of a normal cell. It has a "pear-like" profile. But unlike the nuclei of the tumor cell of Figure 1, the nucleus is a continuous, 


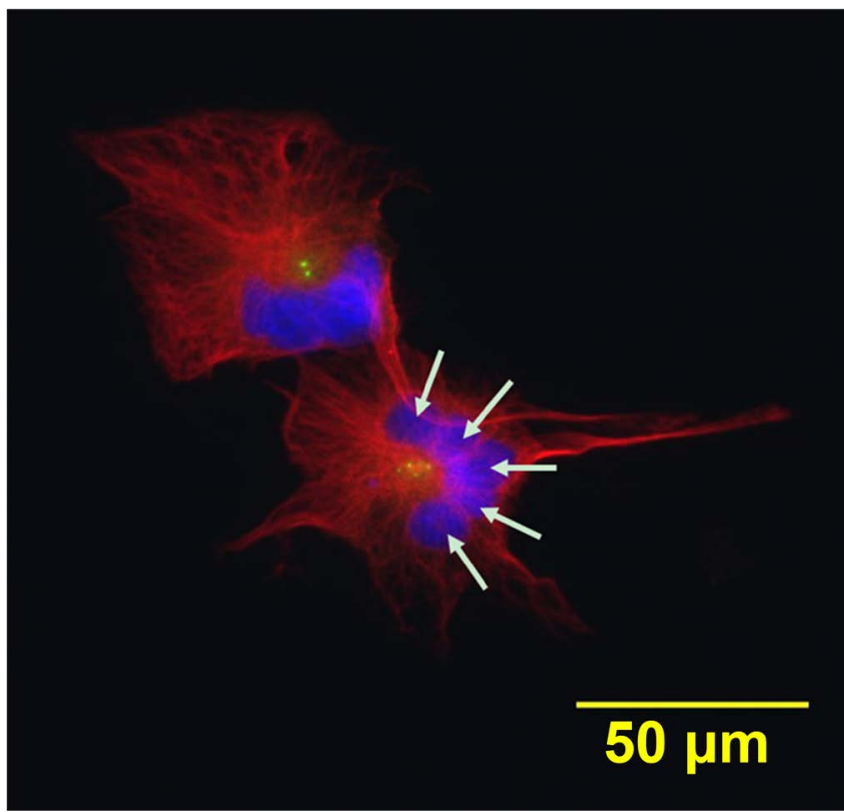

Figure 1. Nucleus division into five parts—the beginning of a tumor.

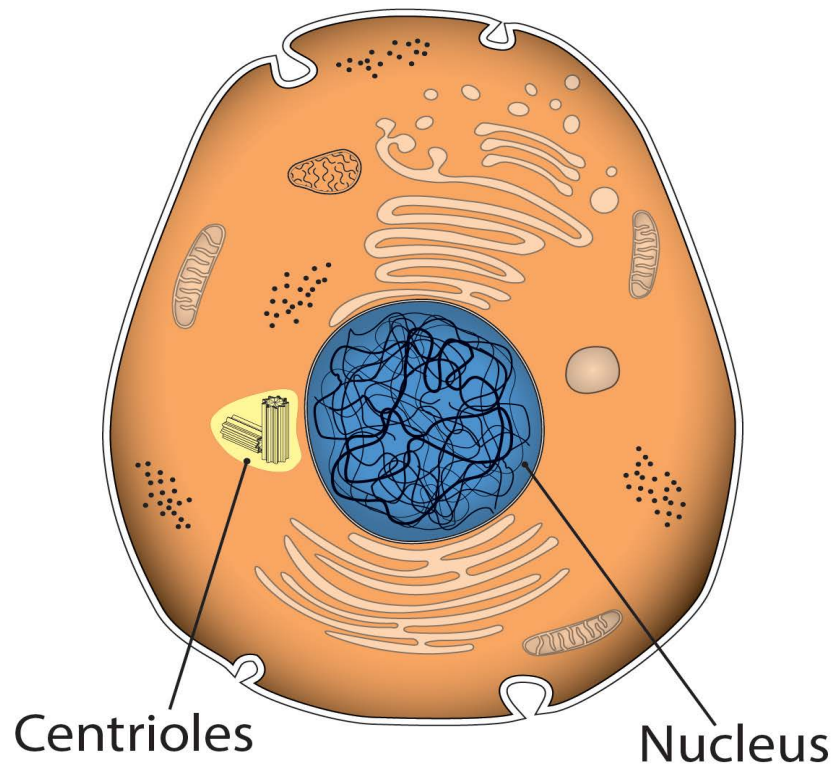

Figure 2. A normal Cell, Its Nucleus and Centrioles.

nearly spherical shape. The nucleus is surrounded by numerous proteins and organelles ("small organs").

Of all the organelles in the cell, the pair of centrioles, shown in Figure 2, are the principal drivers of cell division and duplication.

The centrioles consist of two hollow perpendicular cylinders, approximately 400 to $500 \mathrm{~nm}$ long, outside diameter $200 \mathrm{~nm}$ and inside diameter $50 \mathrm{~nm}$.

Looking closer at the centriole pair, we see that one centriole is slightly longer than the other and that the shorter one is attached at the side of the base of the longer one. 
Looking even closer, we see that each centriole consists of nine blades of microtubules, extending along the length of the centriole, as presented in Figure 3 and Figure 4. A "microtubule" itself is a long hollow cylinder approximately 400 to $500 \mathrm{~nm}$ in length, $25 \mathrm{~nm}$ in outside diameter, $15 \mathrm{~nm}$ in inside diameter, and consequently a wall thickness of $5 \mathrm{~nm}$.

The proximal ends of the centriole pair are immersed in a sea of electron dense proteins, known as the "centrosome".

It is not known exactly how a centriole pair gets duplicated. But the sequence appears to involve only a few of the many proteins in the centrosome. Since a centriole consists primarily of microtubules growing out of the centrosome, the centrosome is also known as the microtubules organizing center, or MTOC.

The proteins not involved in direct centriole formulation probably produce supporting structures.

Just prior to the development of a new pair of centrioles perpendicular to, and near the bases (proximal ends), of the existing centrioles, Asterless protein (AsP) is released and becomes attached to one of the exteriors of a microtubule blade set. Of the nine possibilities, it is not clear which one will be selected. This AsP attachment occurs for both of the centriole pairs (the centrioles with the AsP attached are known as "mother" centrioles).

Next, the AsP recruits Plk 4, the principal protein in the duplication process. The Plk 4 deposits itself on to the AsP and then expands to form a base for the structure of a new centriole. Specifically, the Plk 4 then obtains yet another protein: SAS6 which in turn expands outward into nine spokes forming the base of the nascent centriole.

In this manner, the original pair of centrioles becomes two pairs. The pairs then separate from each other and the newer (or younger) of the pairs begins to move about the nucleus to the diametrically opposite side. During this movement, this younger centriole pair continues its development to maturity.

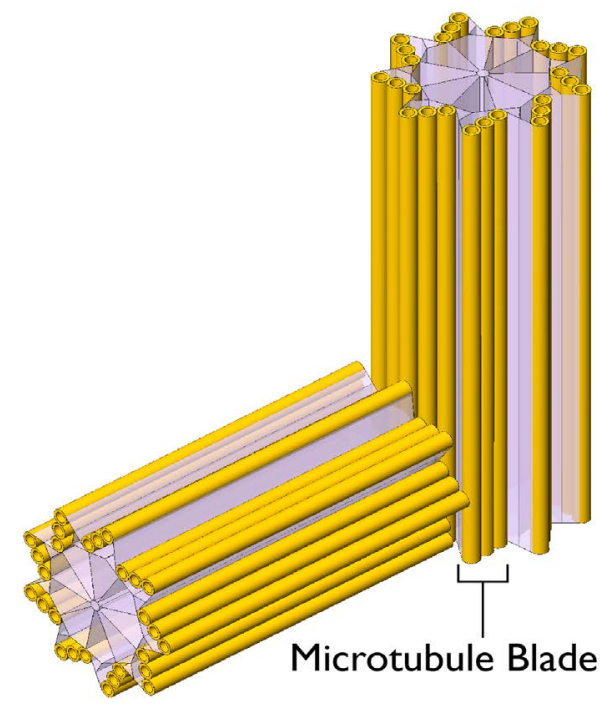

Figure 3. A representation of centriole microtubule blades. 


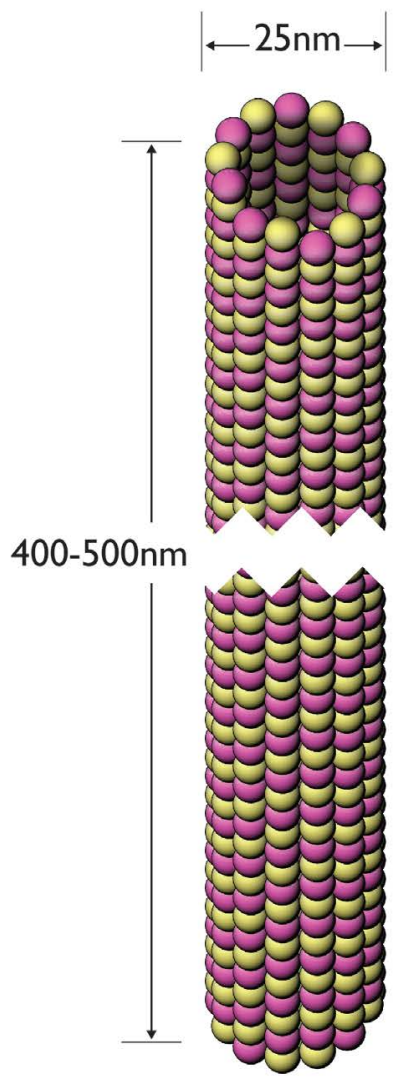

Figure 4. A side view of a microtubule blade.

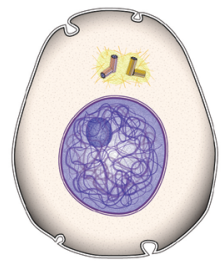

INTERPHASE

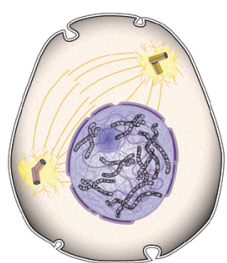

EARLY PROPHASE

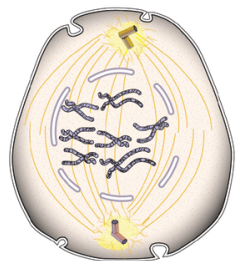

LATE PROPHASE

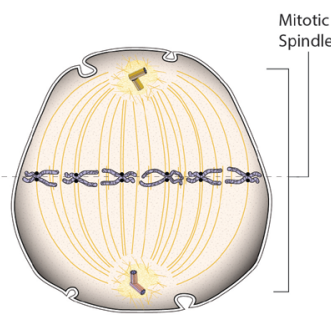

METAPHASE

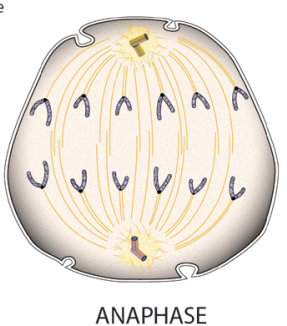

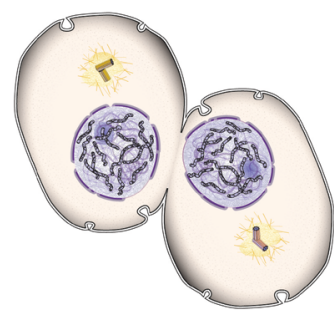

CYTOKINESIS

Figure 5. A Sketch of normal cell division.

Once the centriole pairs are at the opposite side of the nucleus, the microtubules begin to lengthen and spread out about the nucleus and form the so-called "mitotic spindle". While this is happening, the nucleus center begins to soften and eject kinetochores-disk like proteins which attach to microtubule ends.

Once the microtubules and kinetochores are connected, the mitotic spindle 
pulls the nucleus apart (symmetrically) and the separating nuclei become the nuclei of two cells. Figure 5 provides a sketch of the process.

\section{Conclusion}

A comparison of the difference between Figure 1 and Figure 5 shows the vast difference between normal and cancer cells. The principal finding is in that in a cancer cell the nucleus is not a single organelle, but instead a set (in this case five) organelles, each of which becomes the nucleus of another cell. That is, the single cell divides into five cells (instead of only two cells).

\section{Postscript}

The principal finding of this paper is the image of Figure 1. Section 2 provides background review information to point out the significance of the Figure 1 image.

\section{Acknowledgements}

SupSport for this research and documentation has been provided by the Schafer Foundation and is sincerely appreciated. The creation of the figures by Mary Schartman is acknowledged. Finally, discovery by Christy Caudill of the multi-nuclei cell, the subject of this paper, is specially acknowledged. Reviewer comments were also helpful.

\section{Conflicts of Interest}

The authors declare no conflicts of interest regarding the publication of this paper.

\section{References}

[1] Alberts, B., Bray, D., Lewis, J., Raff, M., Roberts, K. and Watson, J.D. (1994) Molecular Biology of the Cell. 3rd Edition, Garland Publishing, New York.

[2] Campbell, N.A. (1987) Biology. Benjamin Cumming Publishing, Metro Park, CA.

[3] Hardin, J., Bertoni, G. and Kleinsmith, L.J. (2015) Becker's World of the Cell. 8th Edition, Pearson Publishing. https://www.pearson.com/us/higher-education.html

[4] Sherma, I.W. and Sherman, V.G. (1983) Biology-A Human Approach. 3rd Edition, Oxford University Press, Oxford.

[5] Mader, S.S. (1985) Inquiring into Life. 4th Edition, W. E. Brown Publishers.

[6] Huston, R.L. (2016) A Review of Centriole Activity, and Wrongful Activity, during Cell Division. Advances in Bioscience and Biotechnology, 7, 169.

https://doi.org/10.4236/abb.2016.73015 